\title{
A AMPLIAÇÃO DA EXPERIÊNCIA LITERÁRIA COMO UM DOS EIXOS PRIORITÁRIOS NA EDUCAÇÃO DE LINGUAGEM: PRIMEIRAS APROXIMAÇÕES
}

\author{
EXPANDING LITERARY EXPERIENCE AS ONE OF THE PRIORITY AXES \\ IN LANGUAGE EDUCATION: FIRST APPROACHES
}

Émilly Todescato | Lattes | emilly.todescato@gmail.com
Universidade Federal de Santa Catarina

Kimberli Sabino | Lattes | kimberli.ariotti@gmail.com Universidade Federal de Santa Catarina

\begin{abstract}
Resumo: O presente artigo tem como objetivo explorar as primeiras aproximações sobre o trabalho de educação linguística, tendo em vista a ampliação da experiência literária como um dos eixos prioritários do ensino de língua portuguesa no Brasil. A discussão enfrentada, sobre o lugar que a leitura do texto literário ocupa nas aulas de Língua Portuguesa, fundamentou-se na teoria histórico-crítica e na pedagogia histórico-cultural, tendo uma abordagem dialógica e histórica, com a finalidade de promover a aproximação do problema com os fundamentos teórico-filosóficos e pedagógicos.
\end{abstract}

Palavras-chave: Linguística. Literatura. Educação Linguística. Linguística Aplicada. Ensino.

\begin{abstract}
This article aims to explore the first approximations about the work of language education, aiming at the expansion of literary experience as one of the priority axes of Portuguese language teaching in Brazil. The discussion regarding the place that reading the literary text occupies in Portuguese language classes was based on historical-critical theory and historical-cultural pedagogy, taking into account a dialogical and historical approach, thus promoting approximation with the theoretical-philosophical and pedagogical foundations.
\end{abstract}

Keywords: Linguistics. Literature. Language education. Applied Linguistics. Teaching. 


\section{Introdução}

A temática desse artigo surge, ou melhor, dá continuidade à necessidade histórica de pensar uma pedagogia revolucionária, ou marxista, como houve no momento pós-ditadura. O momento histórico foi marcado pelo debate sobre o modelo educacional, que era o tradicional. Pôde ser discutido esse modelo educacional e perante as duas possibilidades - de ser revolucionário ou ser neoliberal -, aponta Saviani (2008, p. 12) que em "uma sociedade como a nossa, de base capitalista, as pedagogias hegemônicas correspondem aos interesses da burguesia, já que esta ocupa posição de classe dominante. E as pedagogias contra hegemônicas correspondem aos interesses do movimento operário.” No mais, as entidades governantes fizeram a opção pelo modelo neoliberal de sociedade e consequentemente de educação, "o que estava na ordem do dia era a realização da revolução democrático-burguesa, a concepção pedagógica adequada a esse processo de transformação da sociedade brasileira se deu pelo movimento escolanovista" (SAVIANI, 2008, p. 14). Dessa forma, a partir da década de 80, a Escola Nova cresce como modelo educacional alternativo, servindo ao projeto neoliberal. Com a possibilidade da escolha entre dois modelos, e, em tempos de obscurantismo beligerante (DUARTE, 2018), parece imperativo rediscutir o projeto educacional que se tem, e parece que essa discussão leva a uma superação dos modelos alinhados à perspectiva neoliberal em favor de modelos alinhados a uma pedagogia revolucionária de fundamento marxista, de concepção dialética na versão do materialismo histórico e atrelando as bases psicológicas à psicologia histórico-cultural (SAVIANI, 2008). Seguindo o imperativo, nesse tempo histórico, de superar os modelos pedagógicos de caráter neoliberal e de questionar o modelo imposto, a pedagogia histórico-crítica coloca-se como fundamental, trazendo seus fundamentos para entender educação como ato de produzir (direta e intencionalmente), em cada indivíduo singular, a humanidade que é produzida histórica e coletivamente pelo conjunto dos homens (SAVIANI, 2008), sendo a prática social o ponto de partida e de chegada da prática educativa.

No entanto, o trabalho educativo (SAVIANI, 2003) - ressaltando, aqui, que o trabalho do professor é ensinar e o do aluno é aprender - possui uma ação intencional. $O$ que se vê em tempos de obscurantismo beligerante (DUARTE, 2018) é a escola se tornando refém do imediatismo e do pragmatismo da cotidianidade, especialmente na sociedade capitalista contemporânea, sendo que os conteúdos escolares têm importância fundamental para que o indivíduo aluno compreenda as

Relações entre sociedade e natureza, do processo histórico pelo qual 
os seres humanos vêm se organizando socialmente para a produção/ reprodução das condições materiais de existência humana e, também, para domínio da riqueza simbólica por meio da qual a humanidade confere sentido as suas obras. (DUARTE, 2018, p. 143)

Os conteúdos escolares nada mais são do que a experiência humana acumulada e sintetizada nas ciências, nas artes e na filosofia. O processo educativo encaminha a conquista da autonomia e da liberdade, à medida que o indivíduo vai se apropriando das riquezas culturais e "forma necessidades e potencialidades ampliadoras de suas atividades e de suas relações com o mundo" (DUARTE, 2018, p. 144). A educação linguística, na perspectiva defendida por Britto (2012), é esse modelo empregado por uma reflexão específica sobre o ensino de língua, da alfabetização (da educação infantil) até o ensino superior. Esse trabalho tem como objetivo discutir o lugar que a leitura do texto literário ocupa nas aulas de Língua Portuguesa.

\section{Formação humana}

Pela perspectiva marxista e, principalmente, pelo momento histórico atual, se faz mais do que necessário ressaltar a importância da arte na formação do indivíduo. A arte como manifestação humana e como campo de conhecimento é parte desse processo de formação humana. Duarte e Martins (2013) ressaltam que

\footnotetext{
Se na organização material da sociedade contemporânea há uma grande distância entre, por um lado, as possibilidades criadas pela capacidade produtiva humana e, por outro, as limitações da vida da maior parte da humanidade, não se pode dizer que as coisas sejam diferentes, no que se refere ao papel que a ciência, a arte e a filosofia têm desempenhado para a vida humana. O conhecimento científico, em que pesem suas limitações, contradições e disputas, obteve avanços enormes na compreensão da natureza (NANDA, 1999). Contudo, boa parte da humanidade sequer tem notícia da existência desse conhecimento e adota comportamentos e valores orientadores da vida, baseados em crenças em seres inexistentes, em paraísos celestes ou infernos de sofrimento eterno. Sem desconsiderarmos que as artes também foram afetadas pela decadência ideológica da sociedade burguesa, entendemos ser inegável que elas acumularam, ao longo da história, uma riqueza capaz de desenvolver os sentidos humanos em múltiplas direções, alcançando níveis muito elevados (LUKÁCS, 1966a, 1966b, 1967a, 1967b). (DUARTE; MARTINS, 2013, p. 69)
}

Dentre as diversas manifestações artísticas está a arte da palavra - a literatura. Primeiramente, há de se considerar, no escopo da teoria marxista, que a linguagem humana é originada a partir do e pelo trabalho, uma vez que o trabalho, antes de tudo, é o fundamento da vida humana, pois é uma condição para a existência social. Entretanto, 
não é todo trabalho uma atividade, pois a atividade carrega a ideia de consciência de um resultado pretendido para a ação, sendo esse o elemento significativo da categoria. Uma atividade humana, para ser de fato trabalho, precisa contar com essa relação dialética entre antecipação na consciência e objetivar a ação, ou seja, prévia-ideação e objetivação precisam estar presentes. Sendo assim, é por meio da atividade que o sujeito produz uma realidade humana e, ao produzi-la, ele humaniza a si próprio, ou seja, "a atividade de trabalho cria, portanto, uma realidade humanizada tanto objetiva quanto subjetiva” (DUARTE, 2013, p. 26) e, de forma dialética, a objetivação e a apropriação são essenciais para a "autoprodução do ser humano por meio da atividade vital humana, o trabalho." (p. 9).

De certo, as ações animais e as atividades humanas vão se diferenciar ao longo do curso da história, pelo fato de que os homens criam ideias e essas ideias carregam em si um embrião para construção objetiva e material da realidade, enquanto os animais agem e produzem para suprir as necessidades básicas, natureza muito diferente da humana. A natureza humana é capaz de produzir e de antever, no âmbito da consciência, o resultado necessário (uma objetivação necessária, um produto necessário, um objeto necessário), pretendido justamente por conta de uma necessidade. Na perspectiva marxista, não há nada de natural, tudo que supera alimentação e segurança é produzido. Deste modo, a própria linguagem é fruto de uma necessidade humana: a comunicação, sendo vital para a atividade de trabalho coletiva. Ainda, quando tomamos linguagem como instrumento, Duarte (2013, p. 28) afirma que "um instrumento não é apenas algo que as pessoas utilizam em sua ação, mas algo que passa a ter uma função social, uma significação que é dada pela atividade social. O instrumento é, então, um objeto que é transformado para servir a determinadas finalidades no interior da prática social", ou seja, a linguagem tem determinadas finalidades no interior da prática social. Eis que

[..] ao reconhecer a centralidade do trabalho na formação humana e, consequentemente, na estruturação do psiquismo, Vygotski historicizou o desenvolvimento de suas propriedades, aliando esse desenvolvimento à reorganização dos mecanismos naturais por decorrência da apropriação da cultura. Postulou que as particularidades psíquicas especificamente humanas se instituem na transformação dos processos naturais - que ligam de modo imediato o ser ao meio - em processos mediados, que dirigem o comportamento humano por intermédio do signo. (MARTINS, 2015, p. 45) 
A própria linguagem, sendo uma manifestação humana e, como visto na perspectiva defendida, devido à formação da consciência, o homem é capaz de "transcender a situação, assim como as opções e os pontos de vista pessoais, para colocar-se na perspectiva universal, entrando em comunicação com os outros e reconhecendo suas condições situacionais, assim como suas opções e seus próprios pontos de vista” (SAVIANI; DUARTE, 2010, p. 422). Assim, a linguagem em sua função instrumental designa que

o real significado do papel do signo na conduta humana só pode ser encontrado na função instrumental que assume. Para explicar essa premissa, ele [Vigotski] recorreu a três proposições: a primeira diz respeito às semelhanças e pontos de contato entre o emprego de ferramentas e o emprego de signos; a segunda visa suas divergências; e a terceira busca indicar as reais correspondências psicológicas entre eles. É no âmbito dessa explicação que a categoria mediação assume centralidade. Em relação às semelhanças e pontos de contato, afirmou que tanto os instrumentos quanto os signos se incluem no conceito mais geral de atividade mediadora, isto é, um tipo de atividade que permite aos que participem dela exercerem entre si, a partir de suas propriedades essenciais, uma influência recíproca da qual depende a consecução do seu objetivo. Portanto, a mediação ultrapassa a relação aparente entre coisas, penetrando na esfera das intervinculações entre as propriedades essenciais das coisas. [...] a mediação é interposição que provoca transformações, encerra a intencionalidade socialmente construída e promove desenvolvimento; enfim, uma condição externa que, internalizada, potencializa o ato de trabalho, seja ele prático ou teórico. (MARTINS, 2015, p. 46)

Portanto, a semelhança entre o domínio de um objeto material e o domínio de um signo é que os dois são elementos que ao serem tomados pelo sujeito, a partir de suas necessidades, contribuem para o processo de objetivação da realidade social, além da apropriação. Nessa perspectiva, a atividade mediadora é tomada em uma relação sujeito-objeto, sujeito-sujeito e sujeito-meio. É a atividade mediadora que permite que um sujeito incida sobre outro, além de incidir sobre a realidade. Ainda, é a realidade social, a interação entre as coisas, que dá significado aos objetos materiais e à própria linguagem, superando a relação aparente entre as coisas e colocando uma ideia de intervinculação das propriedades essenciais dos objetos (materiais ou imateriais), sempre em relação dialética. De encontro, o psiquismo humano se manifesta pelos modos de funcionamento naturais e as formas instrumentais,

Os primeiros, decorrentes do processo de evolução e comuns aos homens e aos animais superiores, foram denominados funções psíquicas elementares; os segundos, caracterizados como funções psíquicas 
superiores, são produtos da evolução histórica e especificamente humanos, ou seja, conquistas do desenvolvimento do ser social. Para Vygotski (1997), o ato instrumental, isto é, o ato mediado por signos, introduz profundas mudanças no comportamento humano, posto que entre a resposta da pessoa e o estímulo do ambiente se interpõe o novo elemento designado signo. O signo, então, opera como um estímulo de segunda ordem que, retroagindo sobre as funções psíquicas, transforma suas expressões espontâneas, naturais, em expressões volitivas, culturais. As operações que atendem aos estímulos de segunda ordem conferem novos atributos às funções psíquicas, e por meio delas o psiquismo humano adquire um funcionamento qualitativamente superior e liberto tanto dos determinismos biológicos quanto do contexto imediato de ação. (MARTINS, 2015, p. 46)

Ou seja, os instrumentos técnicos, os primeiros, transformam o objeto externo, e os signos, os segundos, têm como objetivo a transformação do próprio sujeito. Ainda, Vigotski (2012 [1995], p. 272) afirma que "el desarrollo del linguaje del niño influye sobre el pensamento y lo reorganiza”, portanto,

As palavras ajudam, em primeiro lugar, a destacar o mais importante e, em segundo lugar, a combinar quaisquer imagens. Em vez de subir o armário ou saltar para pegar a bola, posso esboçar em um minuto dois ou três planos de ação e eleger um deles. Vemos, então, que a solução de uma tarefa por meio da palavra ou de ação são completamente distintas. (VIGOTSKI, 2012 [1995], p. 276, tradução nossa)

Assim, a formação do ser humano em sua manifestação histórica concreta na forma social capitalista, ou seja, a perspectiva histórico-ontológica da formação humana, apresentada por Saviani e Duarte (2010), vê o comportamento dos indivíduos, assim como o comportamento linguístico, como um produto social, pertencente a uma determinada forma de sociedade. A importância da educação, na perspectiva de formação humana, se dá, principalmente, pelo fato de a educação emergir como "uma comunicação entre pessoas livres em graus diferentes de maturação humana." (SAVIANI; DUARTE, 2010, p. 423). Nesse sentido,

as artes educam a subjetividade tornando-nos capazes de nos posicionarmos perante os fenômenos humanos de uma forma que ultrapasse o pragmatismo cotidiano. As artes trazem para a vida de cada pessoa a riqueza resultante da vida de muitas gerações de seres humanos, em formas condensadas, possibilitando que o indivíduo vivencie, de forma artística, aquilo que não seria possível viver com tal riqueza na sua cotidianidade individual. (DUARTE, 2016, p. 115) 
Cabe retomar que o sistema capitalista continuou a conduzir

a divisão da população em classes diferentes e, portanto, no antagonismo entre as classes dominantes e as classes oprimidas. Em consequência, os interesses das classes dominantes converteram-se no elemento propulsor da produção, enquanto esta não se limitava a manter, bem ou mal, a mísera existência dos oprimidos. (ANTUNES, 2004, p. 26)

A literatura, sendo uma manifestação artística, tem a capacidade de levar o leitor a explorar além da vida cotidiana. Nessa perspectiva, além da emancipação do trabalho no sistema capitalista, ou melhor, de uma nova forma de conceber o trabalho que não as determinadas pelo capital atualmente, sendo o trabalho o pilar central da natureza humana, o que nos diferencia dos outros animais, é fato que o homem precisa produzir a sua própria existência para garanti-la, e faz transformando através do trabalho. Para isso, na educação, sendo ela um fenômeno próprio dos seres humanos, a mediação teórico-metodológica (DUARTE, 2017), juntamente com uma visão científica de como pensar o mundo e a presença da escola, se torna condição para uma reflexão sobre a educação. Assim, as teorias e perspectivas aqui defendidas visam a formação humana além de conteúdos de todas as áreas e do desenvolvimento da dimensão cognitiva, mas também o desenvolvimento da dimensão cultural das relações interpessoais, da criatividade, da afetividade, dos valores. Ou seja, a educação omnilateral, com o desenvolvimento integral do indivíduo em todas as potencialidades e em todos os sentidos.

\section{Educação linguística}

Para discutir as questões relativas à educação linguística, é necessário perpassar, ainda que brevemente, pelas concepções de educação. Assim como afirmou Saviani (1984), a natureza da educação e a natureza humana estão interligadas. Uma vez que, em oposição a outros animais, o homem precisa produzir sua própria existência, adaptando a natureza a si e, consequentemente, a transformando, o que diferencia o homem de outros animais, conforme o autor, é o trabalho, pois através dele são extraídos da natureza os meios de sobrevivência necessários para que se crie um mundo humano.

Partindo desse raciocínio, Saviani (1984) afirma que a educação, além de ser uma exigência para o processo de trabalho, é também, em si mesma, um processo de trabalho. É, portanto, o que o autor chama de "trabalho não-material", uma vez que produz materiais abstratos, como conhecimentos e valores. Sendo assim, o trabalho com a educação tem como premissa produzir em cada indivíduo, de forma direta e proposital, "a humani- 
dade que é produzida histórica e coletivamente pelo conjunto dos homens" (SAVIANI, 1984, p. 2). Ou seja, o objeto da educação são os elementos da cultura humana que necessitam ser incorporados por cada indivíduo e, também, a busca pela maneira mais adequada para alcançar esse objetivo.

Em se tratando da relação entre educação e trabalho, é inevitável discorrer sobre as concepções marxistas. Sabe-se que a temática educacional não ocupa um papel central na obra de Marx, de modo que não há, de forma explícita, uma teoria a respeito da educação, tampouco orientações a respeito do processo de ensino-aprendizagem. Entretanto, é possível identificar em sua obra uma preocupação com a temática educacional, principalmente no que tange ao papel que a educação tem nas transformações do âmbito social, e não apenas no desenvolvimento individual.

A partir da união entre escolaridade e trabalho, conforme Ferreira e Bittar (2008), Marx engendrou sua concepção educacional, compreendendo que uma aliança entre a educação e o poder que o homem tem de transformar o ambiente externo seria capaz de formar o "homem novo", sendo este "consciente das suas potencialidades históricas, que embrionariamente já se manifestava nos marcos da própria Revolução Industrial” (FERREIRA; BITTAR, 2008, p. 638).

Marx versa sobre uma educação voltada para a formação de um homem omnilateral, que harmoniza seu tempo de trabalho com o seu tempo livre. Segundo Ferreira e Bittar (2008), para Marx e Engels é necessário abordar as questões socioeconômicas, bem como a luta de classes que sustentam a educação para que se possa falar dela, eliminando seu aspecto idealista e neutro e declinando qualquer memória romântica antiindustrial.

Essa omnilateralidade, para Marx e Engels, está relacionada ao trabalho, "que é uma das categorias fundamentais do materialismo histórico, ocupando, por conseguinte, lugar central na proposta pedagógica marxiana” (FERREIRA; BITTAR, 2008, p. 641). Conforme a visão marxiana, o aspecto negativo relativo ao conceito de trabalho é justamente a unilateralidade do homem, advinda de um processo de alienação a partir da divisão do trabalho, em que o trabalhador se sente fora de si quando no trabalho, como se não pertencesse a si mesmo. Dessa forma, a proposta educacional marxista demonstra ser radicalmente humanista. Conforme Ferreira e Bittar (2008), para o marxismo, tanto o corpo quanto a espiritualidade do indivíduo devem ser desenvolvidos simultaneamente. A formação omnilateral, será, então, a "transformação da individualidade tendo-se como referência a luta histórica da humanidade por condições que permitam uma existência verdadeiramente livre e universal” (DUARTE, 2017, p. 121). 


\subsection{Letramento e conhecimento}

Um dos fenômenos históricos que se realiza e se produz a partir do trabalho humano é a própria língua. Ela é, segundo Britto (2012), “uma totalidade, que, constituída na história humana, institui os sujeitos, sendo marca de identidade, condição de pensamento, modo fundamental de relacionamento e intervenção no mundo”. A língua, além de ser uma manifestação de identidades não só de indivíduos como também de nações, é poder. Especialmente o domínio sobre a linguagem, como a leitura e a escrita.

De acordo com Bourdieu (1998 apud BRITTO, 2012), essa expressão de poder se manifesta a partir do conceito que chamou de língua legítima, ou seja, uma língua que expressa poder e é reconhecida pelo Estado. A partir dessa crença, nasce o preconceito linguístico e todos os seus desdobramentos; a utopia de um modelo correto da língua e estereótipos criados envolvendo a cultura. Questões como essa geram um debate pedagógico acerca de como se deve ensinar a língua materna e do que ela tem a ensinar.

Conforme Britto (2012), através da escola são partilhados os conhecimentos formais, e a ela cabe o encargo de uma Educação Linguística que não se reduza a uma aprendizagem desordenada tal como é feito no cotidiano. Portanto, cabe à escola assegurar que seus alunos tenham acesso não só à escrita, como também aos discursos constituídos a partir dela, uma vez que a aprendizagem da escrita e de todos os outros conteúdos transmitidos por ela são essenciais para a formação do sujeito e se efetivam através da reflexão.

Ainda no que tange o ensino da escrita, o autor chega à conclusão de que existem duas vertentes de ensino: a tecnicista e a política. Enquanto a primeira parte do pressuposto de que o letramento é um conhecimento abstrato, portanto não associado a outros conhecimentos, tomando forma de competência e idealizando um modo de ação ideal para todos, a segunda não faz essa dissociação em relação aos outros conhecimentos, portanto, segundo essa vertente, o saber da escrita não independe do conhecimento. Dentro da discussão da educação linguística, os estudos do letramento têm avançado como possibilidade teórica para o enfrentamento desse modelo neoliberal, no entanto, ele é insuficiente.

Dessa forma, conforme Duarte (2004 apud BRITTO, 2007, p. 29), “[...] devemos lutar por uma educação que produza nesses alunos necessidades de nível superior, necessidades que apontem para um efetivo desenvolvimento da individualidade como um todo". Ao concordar com o raciocínio do autor, Britto (2012) frisa que é preciso recusar a ideia de um letramento voltado para os usos cotidianos da escrita e que atribui à leitura è̀ escrita o caráter de competência, uma vez que assim é reforçada a ideia de uma educação subserviente às demandas produtivas, desfavorável à formação intelectual. 


\title{
3.2 Educação linguística
}

Para discutir o ensino da língua na educação escolar, Britto (2012) parte de dois pressupostos. Primeiro, de que a principal função da educação escolar é auxiliar no desenvolvimento intelectual e social dos alunos. Segundo, de que a educação linguística deve partir de uma ação pedagógica que faça com que os alunos consigam conceber língua e linguagem como fenômenos históricos que são, além de entender seu funcionamento, bem como uso, formas e modos de utilização na forma oral e escrita, a fim de, além de estudar e aprender, viver sua subjetividade.

Partindo da inferência de Geraldi (1996), de que a língua é um produto histórico em constante atualização enquanto parte da interação na sociedade, Britto (2012) ressalta a concepção do autor de que:

\begin{abstract}
A língua nunca pode ser estudada ou ensinada como produto acabado, pronto, fechado em si mesmo. De um lado, porque sua "apreensão demanda" apreender no seu interior as marcas de sua exterioridade constitutiva (e por isso o externo se internaliza); de outro lado, porque o produto histórico - resultante do trabalho discursivo do passado - é hoje condição de produção do presente que, também se fazendo história, participa deste mesmo produto, sempre inacabado, sempre em construção. (GERALDI, 1996, p. 28 apud BRITTO, 2012, p. 85)
\end{abstract}

Sendo assim, fica evidente a importância da educação linguística. Além disso, o conhecimento da língua, bem como o próprio uso da escrita, é essencial para a inserção social, uma vez que, seguindo Britto (2012), vivemos em uma sociedade grafocêntrica. Entretanto, como bem lembra o autor, o conhecimento da leitura e da escrita não está dissociado de outros conhecimentos objetivos, tendo em vista que, segundo Geraldi (1996, p. 46 apud BRITTO, 2012, p. 87), “a aprendizagem da escrita se dá concomitantemente à aprendizagem dos conteúdos referenciais associados à escrita”.

Diante do fato de vivermos em uma sociedade de classes, a posse da modalidade escrita ainda está desigualmente distribuída, ou seja, quem a domina são os grupos de poder econômico e político mais elevado. Entretanto, conforme esclarece Britto (2012), tanto os discursos públicos, quanto as propostas pedagógicas não concebem a escrita como estando relacionada ao conhecimento e ao poder. $\mathrm{O}$ que se tem é uma ideia de formação voltada para os usos cotidianos, afastada do objetivo de formar sujeitos independentes. Segundo o autor, essa busca por indivíduos que ajam de acordo com as determinações do sistema se justifica a partir de uma pretensão de que esses indivíduos sejam produtivos, capazes de seguir instruções, assumindo e respeitando valores ideológicos. 
Portanto, para os educadores que almejam uma educação voltada para a emancipação dos sujeitos, fica o desafio de desenvolver práticas de ensino apropriadas para tal. Britto (2012) explica que a educação linguística tradicional é voltada para uma ideia de correção da língua, ou seja, da existência de uma língua padrão, e é gerida, também, pela gramática tradicional. Além disso, tem-se o ensino de leitura e redação com associações de textos canônicos com escritas cotidianas. $\mathrm{O}$ autor ressalta que as reformulações do ensino de Língua Portuguesa estão fadadas ao fracasso se insistirem em ater-se ao dilema normativo de como ensinar certo. Segundo ele, a pergunta correta a se fazer diz respeito às razões e finalidades do ensino da língua. É preciso reconhecer que

\begin{abstract}
assumindo que só faz sentido ensinar o que o outro não sabe e que qualquer falante nativo do Português sabe Português, há conhecimentos significativos a serem explorados. Faz todo o sentido tomar a língua como objeto de investigação e conhecimento numa perspectiva que permita a ampliação da percepção do fenômeno da linguagem, independente do uso prático e cotidiano. (BRITTO, 2012, p. 93)
\end{abstract}

Portanto, Britto (2012) conclui que a educação escolar deve ter como objetivo a expansão tanto do conhecimento de língua quanto o de mundo, não somente a correção de acordo com um modelo padrão da língua supostamente correto. Além disso, segundo o autor, é preciso rearranjar a concepção sobre leitura, pois é um engano pensar que o objetivo da educação linguística seja desenvolver um gosto pessoal da leitura e escrita, pois a educação escolar deve favorecer o desenvolvimento de um senso crítico e de conhecimentos que transcendem a vida cotidiana.

\title{
4 Experiência literária
}

Para além da organização de conhecimentos e aprendizagem, de aprofundamento e sistematização do conhecimento, a escola como lugar de formação é "o lugar, enfim, em que a pessoa, reconhecendo-se no mundo e olhando para o que a cerca, imagine o que está para além do aqui e do agora." (DUARTE, 2015, p. 36). Sendo assim, tomando como referência o documento oficial da Base Nacional Comum Curricular (2019, s.p.), o qual toma a leitura como um dos eixos prioritários do ensino de Língua Portuguesa, este eixo compreende

as práticas de linguagem que decorrem da interação ativa do leitor/ ouvinte/espectador com os textos escritos, orais e multissemióticos e de sua interpretação, sendo exemplos as leituras para: fruição estética de 
textos e obras literárias; pesquisa e embasamento de trabalhos escolares e acadêmicos; realização de procedimentos; conhecimento, discussão e debate sobre temas sociais relevantes; sustentar a reivindicação de algo no contexto de atuação da vida pública; ter mais conhecimento que permita o desenvolvimento de projetos pessoais, dentre outras possibilidades. Leitura no contexto da BNCC é tomada em um sentido mais amplo, dizendo respeito não somente ao texto escrito, mas também a imagens estáticas (foto, pintura, desenho, esquema, gráfico, diagrama) ou em movimento (filmes, vídeos etc.) e ao som (música), que acompanha e cossignifica em muitos gêneros digitais.

Aponta-se os dois aspectos centrais que competeriam ao ensino de língua, os quais são "questões especificamente linguísticas" e "experiência literária”, concebidos como conhecimentos historicamente acumulados sobre/pela linguagem. Assim, ressalta Duarte (2015) que além de a leitura ser uma ação intelectual metacognitiva, ler é uma possibilidade para compreender o mundo, intervir na ordem social, produzir conhecimentos e realizar o autoconhecimento, pois uma parte importante da "produção da humanidade está escrita, se fez na e pela escrita e, por isso, o pleno acesso a ela implica a leitura desenvolta e articulada." (DUARTE, 2015, p. 67).

O valor da leitura, determina Duarte (2015), é um produto construído historicamente. Cada leitura tem um motivo e determinante, seus resultados e finalidades. Ler literatura, como forma de ser e estar na história, é um trabalho exigente e incômodo e o "prazer de ler deve vir do desenvolvimento da consciência e da capacidade de estudar, de pensar o mundo sistematicamente, de fantasiar e fabular sem simplesmente consumir a fantasia industrial" (DUARTE, 2015, p. 73). Ao que compete ao ensino de literatura, ao porquê ensinar literatura, pontua Britto (2003, p. 112) que

\footnotetext{
promover literatura, promover leitura enquanto ação política significa que estamos interessados não em promover a leitura em si, mas sim em promover um conjunto de valores e comportamentos humanos dignos, necessários para a própria condição humana, e que estão, de alguma maneira muito importante, expressos e fundamentados na experiência artística.
}

Entende-se ser possível uma educação que fomente a autonomia intelectual e moral por meio da transmissão das formas mais elevadas e desenvolvidas do conhecimento socialmente existente (DUARTE, 2003). Ainda, a literatura leva o leitor para além dos limites de sua vida cotidiana, uma vez que 
o leitor é confrontado com as maneiras pelas quais cada personagem se posiciona perante o mundo, sua vida e perante as demais pessoas. A individualidade do grande personagem está sempre em relação com as de outros personagens. E essas relações entre os personagens empurram o leitor a uma tomada de consciência sobre aspectos da vida humana que passam despercebidos a consciência imersa na cotidianidade. (DUARTE, 2016, p. 93)

Fritzen (2017) indica que se deve aproximar os alunos dos clássicos da literatura levando-os a "um contato mínimo e comum com determinado patrimônio estético-literário que lhe compete interpretar para compreender-se a si e ao outro no quadro cultural a que pertence" (FRITZEN, 2017, p. 118). Viemos, novamente, nos deparar com o problema de o lugar que a leitura do texto literário ocupa nas aulas de Língua Portuguesa. Apesar de haver a aula de leitura, a literatura não é trabalhada no cotidiano como educativo. A experiência literária promove o investimento intelectual e contribui para que se possa ultrapassar a aplicação funcional e imediata, para que não continuemos presos no pragmatismo. No viés do entretenimento, a leitura literária é reduzida apenas à diversão, perdendo a capacidade formativa e promovedora de indagações sobre a vida e sobre o mundo.

Quando se trata da ação pedagógica, há a necessidade de se explorar e articular as variadas dimensões do texto com a formação do gosto (BRITTO, 2012) e a "especulação intelectual”. Além de encantar o leitor, a ação pedagógica terá efeito de formação intelectual e cidadã, quando se insere no ambiente do indivíduo e tem significância para as maneiras que ele vê e interpreta o mundo. Os próprios documentos nacionais afirmam que a prática de leitura tem efeito na "formação intelectual e cidadã" das crianças e dos jovens que frequentam a escola.

\section{Considerações}

Para fechar o fio da meada, fica esclarecido que a literatura como possibilidade de conhecimento (ampliação) só se converte como tal se for instrumento para compreensão da realidade social. Sendo a literatura a leitura prioritária da escola, adota-se aqui a perspectiva de que a educação literária deve viabilizar o processo de objetivação humana e a fruição estética. O problema aqui tratado como primeiras aproximações está, mais do que nunca, localizado em um momento histórico que precisa da participação em debates sobre educação.

A literatura, como conhecimento clássico, deve estar nas escolas e convergir com seus objetivos de aprendizagem, os quais possibilitem a construção da humanização, con- 
siderando pontos relevantes para a formação de uma educação emancipadora. A leitura de literatura promove tensões criativas e estimuladoras de uma personalidade ativa e criativa, numa perspectiva que implica a transcendência da experiência cotidiana e imediata. Apenas com um programa contínuo e consistente, lograremos sucesso nesta empreitada.

\section{Referências}

ANTUNES, Ricardo. A dialética do trabalho. São Paulo: Expressão Popular, 2004.

BRASIL. Base nacional comum curricular. Brasília: MEC/SEF, 2019. Disponível em: http://basenacionalcomum.mec.gov.br/a-base. Acesso em: 21 set. 2019.

BRITTO, Luiz Percival Leme. Contra o consenso - cultura escrita, educação e participação. Campinas: Mercado de Letras, 2003.

BRITTO, Luiz Percival Leme. Escola, ensino de língua, letramento e conhecimento. Calidoscópio (Unisinos), v. 05, p. 24-30, 2007.

BRITTO, Luiz Percival Leme. Inquietudes e desacordos: a leitura além do óbvio. Campinas, SP: Mercado de Letras, 2012.

DUARTE, Newton. A individualidade para si: contribuição a uma teoria histórico-crítica da formação do indivíduo. 3. ed. Campinas: Autores Associados, 2013.

DUARTE, Newton. Educação escolar e formação humana omnilateral na perspectiva da pedagogia histórico-crítica. In: LOMBARDI, José Claudinei. (Org.). Crise capitalista e educação brasileira. 1. ed. Uberlância: Navegando, 2017. p. 101-122.

DUARTE, Newton. O currículo em tempos de obscurantismo beligerante. Curitiba, PR: Revista Espaço do Currículo, v. 11, n. 02, p. 139-145, mai./ago. 2018.

DUARTE, Newton. Relações entre conhecimento escolar e liberdade. Cadernos de Pesquisa: São Paulo, v. 46, n. 159, p. 78-102, mar. 2016.

DUARTE, Newton. Sociedade do conhecimento ou sociedade das ilusões? Quatro ensaios crítico-dialéticos em filosofia da educação. 1. ed. Campinas: Autores Associados, 2003.

DUARTE, Newton; MARTINS, Ligia Márcia. As contribuições de Aleksei Nikolaevich Leontiev para o entendimento da relação entre educação e cultura em tempos de relativismo pós-moderno. In: FERRO, Olga Maria dos Reis; LOPES, Zaira de Andrade. (Org.).Educação e cultura: lições históricas do universo pantaneiro. 1. ed. Campo Grande: Editora da UFMS, 2013. p. 49-74.

FERREIRA JR., Amarilio; BITTAR, Marisa. A educação na perspectiva marxista: uma abordagem baseada em Marx e Gramsci. Interface - Comunic., Saúde, Educ., v. 12, n. 26, p. 635-646, jul./set. 2008.

FRITZEN, Celdon. O entorno da pergunta "O que significa ensinar literatura? reflexões sobre seu lugar e papel na Educação Básica”. In: CECHINEL, André; SALES, Cristiano de. (org.). O que significa ensinar literatura? Florianópolis: EdUFSC; Criciuma: Ediunesc, 2017. 
MARTINS, Lígia Márcia Martins. A internalização de signos como intermediação entre a psicologia histórico cultural e a pedagogia histórico-crítica. Germinal: Marxismo e Educação em Debate, Salvador, v. 7, n. 1, p. 44-57, 2015.

SAVIANI, Dermeval. Sobre a natureza e especificidade da educação. Em aberto, Brasília, ano 3, n. 22, jul./ago. 1984.

SAVIANI, Dermeval. Teorias pedagógicas contra hegemônicas no Brasil. Revista do Centro de Educação e Letras da Unioeste - Campus de Foz do Iguaçu, v. 10, n. 2, p. 11-28, 2008.

SAVIANI, Dermeval; DUARTE, Newton. A formação humana na perspectiva históricoontológica. Revista Brasileira de Educação, v. 15, n. 45, p. 422-590, 2010.

VIGOTSKI, Lev Semenovich. Tomo III. Edición em lengua castellana. Madrid: Machado Grupo de Distribución, 2012 [1995]. 